\title{
DA RECENTE LEGISLAÇÃO SOBRE INOVAÇÃO E SEUS EFEITOS PARA AS UNIVERSIDADES FEDERAIS
}

\section{THE NEW LEGAL FRAMEWORK OF INNOVATION AND ITS CONSEQUENCES FOR BRAZILIAN FEDERAL UNIVERSITIES}

\author{
${ }^{1}$ Davi Monteiro Diniz \\ ${ }^{2}$ Rúbia Carneiro Neves
}

\section{RESUMO}

Este estudo analisa os efeitos, para as universidades federais, decorrentes de recentes alterações legislativas editadas na Emenda Constitucional 85/2015 e na Lei 13.243/2016, conhecida como marco legal da inovação. Conjugando abordagens de direito público e de direito privado, ele compara a realidade jurídica anterior com a atual, analisando os efeitos provocados pelo marco legal da inovação para a criação de conhecimento inovador no âmbito das universidades federais e sua difusão para a sociedade, nas esferas pública e privada.

Palavras chaves: Constituição; Universidade; Tecnologia; Conhecimento Inovador; Marco Legal da Inovação.

\begin{abstract}
This paper considers the main effects of the recent Brazilian law changes concerning the legal framework of innovation as implemented by Constitutional Amendment $n^{\circ}$ 85/2015 and Federal Law $\mathrm{n}^{\circ}$ 13.243/2016. Combining public law and private law perspectives, a descriptive analysis of the new legal framework of innovation is offered, focusing on its consequences for Brazilian federal universities and their capacity to create and spread innovative knowledge to public and market sectors.
\end{abstract}

Keywords: Constitution; University; Technology; Innovative Knowledge; Legal Framework of Innovation.

\footnotetext{
${ }^{1}$ Doutor em Direito pela Universidade Federal de Minas Gerais - UFMG, Belo Horizonte, (Brasil). Professor Adjunto da Universidade de Brasília - UNB, Distrito Federal, (Brasil). E-mail: davidiniz@ unb.br

${ }^{2}$ Doutora em Direito Comercial pela Universidade Federal de Minas Gerais - UFMG, Belo Horizonte, (Brasil). Profa. Adjunta I, da Faculdade de Direito da Universidade Federal de Minas Gerais. E-mail:

rubiacneves@gmail.com
} 


\section{INTRODUÇÃO}

Este estudo analisa os efeitos, para as universidades federais, decorrentes de recentes alterações legislativas editadas na Emenda Constitucional $85 / 15^{3}$ e na Lei $13.243 / 16^{4}$ a respeito do desenvolvimento da inovação e da respectiva transferência do conhecimento produzido para a sociedade, nas esferas pública e privada. Resultado de análise comparativa entre o estado anterior às mudanças legais e os novos contornos traçados, o ensaio foi elaborado mediante revisão bibliográfica e auxílio da metodologia correspondente à vertente dogmática, justificada pela capacidade de explicar as interações entre Direito Público e Direito Privado pertinentes ao tema, bem como pelo relevo das modificações para a promoção do desenvolvimento do sistema produtivo nacional e regional do país.

Nele se investiga em que medida as referidas alterações legislativas, ao tratarem detalhadamente a respeito da inovação, ampliaram as possibilidades das universidades federais, na qualidade de Instituições Científicas, Tecnológicas e de Inovação - ICTs, de gerar conhecimento inovador que não se restrinja à produção de figuras de propriedade intelectual voltadas a proteger o uso exclusivo de determinada tecnologia, para em seguida se avaliar o alcance das novas figuras jurídicas disponíveis.

\section{LEGISLAÇÃO SOBRE INOVAÇÃO: A QUE SE REFERE O MARCO LEGAL DE INOVAÇÃO}

A expressão "marco legal da inovação" vem sendo empregada (RAUEN, 2016) para identificar dispositivos legais editados em 2016 voltados a promover a geração e a difusão de conhecimento inovador por entes públicos e por entes privados. Entretanto, deve-se destacar, para um melhor entendimento dessas mudanças, a Emenda Constitucional 85/15 (E.C. 85/15), que tratou da inovação no texto constitucional, bem como a Lei 13.243/16, a qual, alterando um conjunto significativo de outras leis, apurou o uso jurídico do termo "inovação", de modo

\footnotetext{
${ }^{3}$ BRASIL. Emenda Constitucional no ${ }^{85 / 2015}$, que altera e adiciona dispositivos na Constituição Federal para atualizar o tratamento das atividades de ciência, tecnologia e inovação,

${ }^{4}$ BRASIL. Lei $\mathrm{n}^{\circ} 13.243 / 2016$, que dispõe sobre estímulos ao desenvolvimento científico, à pesquisa, à capacitação científica e tecnológica e à inovação e altera a Lei no 10.973, de 2 de dezembro de 2004, a Lei no 6.815, de 19 de agosto de 1980, a Lei no 8.666, de 21 de junho de 1993, a Lei no 12.462 , de 4 de agosto de 2011, a Lei no 8.745 , de 9 de dezembro de 1993, a Lei no 8.958, de 20 de dezembro de 1994, a Lei no 8.010 , de 29 de março de 1990, a Lei no 8.032, de 12 de abril de 1990, e a Lei no 12.772, de 28 de dezembro de 2012, nos termos da Emenda Constitucional no 85, de 26 de fevereiro de 2015.
} 
a possibilitar que ele sirva como um eixo conceitual em torno do qual gravitam consequências legais relevantes.

Sobre tais mudanças, deve-se inicialmente analisar as alterações constitucionais, já que elas estabelecem a moldura na qual a legislação infraconstitucional poderá produzir seus efeitos, para em seguida avaliar as mudanças implementadas pelo legislador ordinário.

\subsection{A Emenda Constitucional 85/15}

A E.C. 85/15, alterando os artigos 23 e 24 do texto constitucional, determinou a competência comum da União e dos entes federados para proporcionar os meios de acesso à cultura, à educação, à ciência, à tecnologia, à pesquisa e à inovação, também lhes conferindo competência concorrente para legislar sobre essas matérias.

Ademais, ela acrescentou novo dispositivo à disciplina das finanças públicas, o art.167, § 5º da Constituição Federativa da República do Brasil de 1988 (C.F.), assim autorizando ocorrer a transposição, o remanejamento ou a transferência de recursos de uma categoria de programação para outra, no âmbito das atividades de ciência, tecnologia e inovação, quando feitas com o objetivo de viabilizar os resultados de projetos restritos a essas funções. Nesses termos, tal poderá ser feito mediante ato do Poder Executivo, sem necessidade da prévia autorização legislativa.

Ao lado dessas significativas alterações, a E.C. 85/15 estabeleceu que a promoção da inovação constitui política pública a ser implementada por todos os entes da República, a ver, União, Distrito Federal, Estados e Municípios. Essa orientação está presente na nova redação oferecida ao art. $213, \S 2^{\circ}$ da C.F., pelo qual as atividades de pesquisa, de extensão e de estímulo e fomento à inovação realizadas por universidades ou por instituições de educação profissional e tecnológica poderão receber apoio financeiro do Poder Público.

Ressalte-se, porém, que os mais relevantes efeitos da inserção do termo "inovação" na dicção constitucional decorrem das mudanças registradas nos art. 218 a 219-B da C.F. Neles se estabelece que a promoção da inovação receberá o mesmo tratamento antes conferido ao desenvolvimento da ciência e da tecnologia. Por essa via, o estímulo à inovação pode ser objeto de políticas públicas integradas, uma vez que autorizados os entes estatais a empregar recursos financeiros, materiais e humanos para realizar ações com esse escopo, tarefa a ser realizada não só pela União, mas também por iniciativa das demais unidades federadas. 
Nessa linha, em conjunto com o desenvolvimento da ciência e a tecnologia, a inovação deve ser promovida e incentivada pelo Estado, o qual oferecerá tratamento prioritário para a pesquisa científica e tecnológica realizada com esses fins, assim compreendendo medidas tais como incentivar a atuação no exterior dos entes públicos e disponibilizar meios e condições especiais de trabalho aos envolvidos nessas atividades, tanto no setor público como no privado.

Destaca-se, contudo, a redação do art. 219, parágrafo único, por dispor que o Estado deverá estimular a formação e o fortalecimento da inovação em entes públicos e privados, apoiando ambientes promotores da inovação, a atuação dos inventores independentes e a criação, absorção, difusão e transferência de tecnologia. É importante notar que este dispositivo dispõe sobre inovação de maneira específica, enfatizando a necessidade de não só desenvolvê-la, mas também de torná-la acessível com o objetivo de efetivar a sua absorção pela sociedade.

A ênfase das mudanças constitucionais está, sem dúvida, no estímulo a que as atividades de ciência, tecnologia e inovação sejam realizadas de forma conjugada entre entes públicos e privados, em integração sistêmica. Assim, há a previsão de se instituir o Sistema Nacional de Ciência, Tecnologia e Inovação (SNCTI), que deverá atuar em regime de colaboração entre entes públicos e privados, articulação a ser estimulada por todas as esferas de governo. Essa cooperação ocorrerá com alcance amplo, mediante o compartilhamento de recursos financeiros, materiais e humanos para o desenvolvimento de projetos de pesquisa, de desenvolvimento científico e tecnológico e de inovação.

Diante do quadro de alterações trazidas pela E.C. 85/15, resta evidente que a promoção da inovação foi constitucionalmente elevada a objetivo a ser perseguido pelo Estado brasileiro, assim se autorizando a alocação e dispêndio de recursos públicos, bem como a formulação de políticas públicas, as quais podem ser implementadas tanto pela União como pelos entes federativos, de modo autônomo ou em colaboração ente si, como também trabalhando em conjunto com entes privados.

\subsection{A Lei 13.243/16 e o Uso Jurídico Atual do Termo "Inovação"}

Como estudado por Benoît (2008), o emprego do termo “inovação" pode ser percebido com enorme variação ao longo da história, registrando-se, inicialmente, sentido negativo, para designar em geral mudanças politicamente indesejadas, até posteriormente ser 
empregado com significado positivo, revolucionário, de alteração desejada, inclusive perdendo parte de seu valor descritivo em face de um atual uso generalizado para adjetivar mudanças em geral.

Nesse contexto, o autor identifica, dentre os vários usos possíveis, a tendência moderna de se empregar o termo "inovação" para significar "invenção tecnológica", um fenômeno que ocorre em evidente proximidade ao desenvolvimento da patente de invenção, instituto jurídico este decorrente da conversão, nos séculos XVII e XVIII, de monopólios de comércio e indústria concedidos pelos reis absolutistas em direitos privados atribuídos ao respectivo inventor e livremente negociados entre este e empresários.

Essa influência, sem dúvida, se fez notar, no Brasil, na Lei 10.973/2004 ${ }^{5}$, que tratou de incentivos à inovação. Nesta Lei, inovação foi inicialmente conceituada como “(...) introdução de novidade ou aperfeiçoamento no ambiente produtivo ou social que resulte em novos produtos, processos ou serviços". Formulada nesses termos, a inovação foi concebida como objeto determinado, a se concretizar em novidade ou aperfeiçoamento capaz de proporcionar novo produto, processo ou serviço.

Ocorre que tal concepção foi significativamente ampliada pela Lei 13.243/16, a qual, alterando a referida Lei de 2004, conceituou inovação como:

\section{(...) introdução de novidade ou aperfeiçoamento no ambiente produtivo e social que resulte em novos produtos, serviços ou processos ou que compreenda a agregação de novas funcionalidades ou características a produto, serviço ou processo já existente que possa resultar em melhorias e em efetivo ganho de qualidade ou desempenho. ${ }^{6}$}

Observa-se, então, que as mudanças constitucionais e legais acima referidas conferem significado jurídico substancial ao termo "inovação", que atuará como referência necessária para se aplicar as novas prescrições normativas tanto nas ações estatais autônomas como nas relações entre Estado e entes privados.

\subsection{Inovação como Categoria Jurídica - Principais Efeitos}

A combinação das determinações trazidas pela EC 85/2015 com o conceito legal de inovação ora expresso na Lei 10.973/2004 aclara o objetivo e o alcance das referidas mudanças legais. Certo está que, para se promover a inovação, assim entendida como o desenvolvimento de conhecimento capaz de melhorar serviços, produtos ou os respectivos

\footnotetext{
${ }^{5}$ BRASIL. Lei $n^{\circ}$ 10.973/2004. Dispõe sobre incentivos à inovação e à pesquisa científica e tecnológica no ambiente produtivo e dá outras providências.

${ }^{6}$ Cf. Lei no $10.973 / 2004$, Art. $2^{\circ}$, IV.
} 
processos de elaboração destes, há ampla autorização para ações estatais com esse escopo, seja mediante a implementação de programas autônomos do Estado, seja este atuando em cooperação ou fomentando entes privados.

Desse modo, o gestor público poderá destinar recursos para a geração, difusão e aplicação de conhecimento inovador, bem como envolver órgãos estatais e servidores públicos para tais fins. Esse aspecto se mostra de especial significado para as universidades federais, porquanto elas ainda são concebidas como autarquias ou fundações públicas, as quais dependem de autorização legal para apoiar suas ações administrativas em geral.

O ponto de partida para se entender o proveito, pelas universidades federais, das ampliações legais efetuadas, está na sua qualificação, pela Lei 10.973/2004, como Instituição Científica, Tecnológica e de Inovação $(\mathrm{ICT})^{7}$. Ressalte-se que as ICTs federais são diretamente estimuladas por aquela Lei a participar da geração de inovação, o que é viabilizado mediante a mitigação das restrições legais a que estão sujeitos em razão de sua condição de entes da administração pública federal.

Cabe, assim, analisar as vantagens centrais oferecidas às ICTs que aproveitam às universidades federais, como estabelecidas pelo marco legal de inovação.

\section{UNIVERSIDADE FEDERAL COMO ICT E O MARCO LEGAL DA INOVAÇÃO}

Uma questão central ao envolvimento da universidade federal com os objetivos do marco legal de inovação é a de como considerar tais objetivos compatíveis com a atividade regular da instituição acadêmica. Para lidar com este problema, as mudanças legais trataram não só de alterar a Lei 10.973/2004, mas também a Lei 8.958/1994, que dispõe sobre fundações de apoio, além de realizar mudanças específicas em pontos da legislação geral administrativa e empresarial, reforçando o apoio ao desenvolvimento de empreendedorismo inovador.

\subsection{Alterações Relevantes na Lei 10.973/2004}

a) Inovação e propriedade intelectual

O modelo inicial delineado pela Lei 10.973/2004 para a relação entre ICTs e entes privados, particularmente para as relações entre universidades e empresários, elegeu a

${ }^{7}$ Cf. Lei no $10.973 / 2004$, Art. 2o, V.

Revista de Direito, Governança e Novas Tecnologias | e-ISSN: 2526-0014 | Curitiba| v. 2 | n. 2 | p. 01 - 23 | Jul/Dez. 2016. 
produção de tecnologia protegida por direitos de propriedade intelectual como central às relações de cooperação entre os envolvidos.

Nessa moldura, o principal valor oferecido pela universidade ao empresário estaria corporificado no desenvolvimento de objetos de conhecimento protegidos por tais direitos. Tal se depreende do conceito de "criação" oferecido pela Lei 10.973/2004, a ver:

(...) criação: invenção, modelo de utilidade, desenho industrial, programa de computador, topografia de circuito integrado, nova cultivar ou cultivar essencialmente derivada e qualquer outro desenvolvimento tecnológico que acarrete ou possa acarretar o surgimento de novo produto, processo ou aperfeiçoamento incremental, obtida por um ou mais criadores. ${ }^{8}$

Assim, a relação universidade-empresa se constituiria contratualmente em torno da produção de conhecimento com o objetivo de desenvolver e transferir à sociedade tais criações, como acima descrito. Essa estreita baliza de atuação vinha sendo criticada (DINIZ; NEVES, 2015), uma vez que restringir as relações entre universidade e empresários a acordos para desenvolver tecnologia protegida por direitos exclusivos, como é o caso da propriedade industrial e similares, encerra o efeito negativo de excluir a interação entre a academia e outras áreas da economia, relevantes tanto ao setor público como ao privado.

Ocorre que, como visto acima, a alteração no conceito de inovação presente na Lei 10.973/2004 permite que se vá além da busca por direitos exclusivos de fabricação de bens em, pelo menos, dois aspectos importantes: o primeiro decorre de se considerar que a atividade inovadora pode se concretizar não apenas a respeito de bens industriais ou no processo de sua produção, mas também pela sua aptidão para melhorar serviços; já o outro se revela pela possibilidade de as melhorias incrementais serem consideradas inovadoras por proporcionarem efetivo ganho de qualidade e desempenho, ou seja, sem necessariamente atingirem os requisitos para serem protegidas por direitos exclusivos de uso industrial, como se exige, por exemplo, para a patente de invenção e o modelo de utilidade.

Resulta, da ampliação dos objetivos compreendidos pelo conceito de inovação, a expansão das possibilidades de remuneração da ICT e seus participantes pelo envolvimento em atividades de inovação, não mais restritas à transferência de tecnologia protegida e ao licenciamento para uso ou exploração de criações, mas agora já se considerando de modo expresso a pesquisa inovadora e a prestação de serviços técnicos especializados necessários à geração e difusão de conhecimento inovador.

b) A política de Inovação da ICT

${ }^{8}$ Cf. Lei ${ }^{\circ}{ }^{10.973 / 2004, ~ A r t . ~} 2^{\circ}$, II. 
Ao se considerar as mudanças implementadas na Lei 10.973/2004, desponta a previsão de que as ICTs de natureza estatal deverão instituir sua política de inovação, consubstanciando-se determinação legal inequívoca no sentido de que a ICT deverá se envolver de modo permanente na geração de conhecimento inovador. Entretanto, também se observa que, ao determinar que essa política discipline temas detalhados, a Lei também trata de aspectos importantes a respeito do envolvimento das ICTs no processo de inovação.

Assim, relativamente à política de inovação de cada instituição, é determinado às ICTs estatais não só que decidam a respeito de seus objetivos estratégicos quanto a desenvolver conhecimento inovador, mas também que considerem as diretrizes necessárias para, em consonância com as prioridades da política nacional de ciência, tecnologia e inovação e com a política industrial e tecnológica nacional: a) apoiar o empreendedorismo e a gestão de incubadoras, inclusive mediante a participação no capital social de sociedades empresárias; b) realizar atividades de extensão tecnológica e prestação de serviços técnicos; c) compartilhar laboratórios, equipamentos, recursos humanos e capital intelectual; d) gerir a propriedade intelectual e de transferência de tecnologia que desenvolver; e) institucionalizar um Núcleo de Inovação Tecnológica, com competências mínimas; f) capacitar recursos humanos em empreendedorismo, gestão da inovação, transferência de tecnologia e propriedade intelectual, e g) estabelecer parcerias para desenvolvimento de tecnologias com inventores independentes, pessoas naturais ou jurídicas que exerçam empresa ${ }^{9}$ e outras entidades ${ }^{10}$.

Essas determinações legais merecem registro detalhado porquanto revelam de maneira expressiva o conjunto de ações que se espera das ICTs públicas, entre elas, as universidades federais.

\section{c) A remuneração do envolvidos no projeto de inovação}

Importante destacar que as mudanças legais pacificaram a possibilidade de a ICT estatal receber contrapartida pelo uso de seus bens e pelo emprego do saber de seus integrantes no desenvolvimento do projeto de inovação ${ }^{11}$.

Outra significativa alteração legal diz respeito à ampliação das possibilidades de remuneração dos participantes no projeto de inovação. Ao lado da figura da retribuição

\footnotetext{
${ }^{9} \mathrm{O}$ empresário (art. 966, Código Civil/2002), a empresa individual de responsabilidade limitada - EIRELI (art. 980-A, Código Civil/2002) e a sociedade empresária (arts. 982 e 985, Código Civil/2002) são as pessoas, aquele, natural e estas, jurídicas, que devem estar registrados na Junta Comercial para poderem exercer regularmente a empresa.

${ }^{10}$ Cf. Lei ${ }^{\circ} 10.973 / 2004$, Art. 15-A.

${ }^{11}$ Cf. Lei $n^{\circ} 10.973 / 2004$, Art. $4^{\circ}$.
}

Revista de Direito, Governança e Novas Tecnologias | e-ISSN: 2526-0014 | Curitiba| v. 2 | n. 2 | p. 01 - 23 | Jul/Dez. 2016. 
variável, a qual já constava ${ }^{12}$, na Lei 10.973/2004, como forma de pagar quantia adicional ao servidor público sem que tal se considerasse parcela permanente de sua remuneração, deve-se notar a atual permissão para que a ICT institua, a servidor ou aluno, diretamente ou por meio de fundação de apoio ou agência de fomento, bolsa de estímulo à inovação aos que participarem do projeto de desenvolvimento de conhecimento inovador ${ }^{13}$.

Percebe-se, então, a autorização legal para que a ICT estatal, aqui em foco as universidades federais, captem recursos mediante o desenvolvimento de projetos de inovação, com repercussões para o seu patrimônio e reflexos na remuneração de docentes, discentes e servidores-técnico-administrativos, mediante a celebração de acordos entre os financiadores e os executores de cada projeto. Presentes, assim, forte tendência de uso de instrumentos contratuais para operacionalização da atividade e dos projetos de inovação, por vezes referida como "contratualização" para o funcionamento de um sistema nacional de pesquisa em ciência, tecnologia e inovação. (LAPERCHE; UZUNIDIS, 2010).

\subsection{Participação das Fundações de Apoio nos Projetos Acadêmicos de Inovação}

Um fato de inegável relevância ocorrido durante a tramitação das medidas a que se refere o marco legal da inovação foi a concordância do Poder Legislativo com um dispositivo legal que concedia maior autonomia gerencial, orçamentária e financeira às ICTs públicas. Entretanto, a proposta foi vetada pelo Poder Executivo, assim reforçando o uso de fundações de apoio pelas universidades federais ${ }^{14}$.

Rememore-se que, como contrapartida à restrita autonomia gerencial, orçamentária e financeira hoje concedida às universidades federais, uma autorização lhes é franqueada para contratar com dispensa de licitação fundações privadas, especialmente qualificadas como fundações de apoio, assim chamadas por apoiarem “(...) projetos de ensino, pesquisa,

\footnotetext{
${ }^{12} \mathrm{Cf}$. Lei $\mathrm{n}^{\mathrm{o}} 10.973 / 2004$, Art. 2o, IV.

${ }^{13}$ Cf. Lei no $10.973 / 2004$, Art. 8o, § 2ㅇ․

${ }^{14}$ Cf. BRASIL. Lei $\mathrm{n}^{\circ} 13.243 / 2016$. Veto. Mensagem $\mathrm{n}^{\mathrm{o}}$ 8, de 11 de janeiro de 2016. Art. 26-B. A ICT pública que exerça atividades de produção e oferta de bens e serviços poderá ter sua autonomia gerencial, orçamentária e financeira ampliada mediante a celebração de contrato nos termos do $\S 8$ o do art. 37 da Constituição Federal, com vistas à promoção da melhoria do desempenho e ao incremento dos resultados decorrentes de suas atividades de pesquisa, desenvolvimento, inovação e produção. Razões do veto: "A atribuição de autonomia gerencial, orçamentária e financeira a Instituição Científica e Tecnológica pública pressupõe a fixação de conceitos e condições para sua viabilização. Com a inexistência da regulamentação do que dispõe o $\S 8^{\circ}$, do art. 37 da Constituição, o dispositivo seria inexequível ou seria aplicado de forma a trazer insegurança jurídica para tais contratos."
} 
extensão, desenvolvimento institucional, científico e tecnológico e estímulo à inovação, inclusive na gestão administrativa e financeira necessária à execução desses projetos." 15

a) Gestão continuada de recursos por fundação de apoio

Nesse contexto, as mudanças legais elegeram as fundações de apoio como meio privilegiado para o desenvolvimento de projetos de inovação, particularmente por a lei conceder às ICTs a faculdade de autorizarem que os recursos destinados a projetos de pesquisa ou de prestação de serviços relacionados com a geração ou difusão de conhecimento inovador sejam repassados diretamente a fundação de apoio $^{16}$, desse modo não se submetendo, neste ponto, às limitações previstas pelo sistema orçamentário-financeiro a que estão ordinariamente sujeitas as entidades da administração federal.

Desse modo, os ganhos da ICT advindos da participação em projetos de inovação poderão ser permanentemente mantidos sob os cuidados de fundação de apoio, proporcionando uma linha de recursos para a ação das universidades federais que não ficará exposta aos principais efeitos do princípio da anualidade orçamentária ${ }^{17}$.

\section{b) A fundação de apoio como núcleo de inovação tecnológica}

A Lei 10.973/2004 já estabelecia a instituição, pelas ICTs, de núcleos de inovação tecnológica com competência para gerenciar o desenvolvimento e a negociação de propriedade intelectual produzida pelas respectivas instituições a ele vinculadas ${ }^{18}$. Entretanto, as mudanças legais alteraram profundamente essa situação, porquanto facultaram atribuir as funções do NIT à pessoa jurídica diversa, podendo inclusive esta ser fundação de apoio ${ }^{19}$.

Nessa condição, a fundação de apoio prestará à ICT outros serviços além do apoio a projetos, cabendo-lhe também zelar pela propriedade intelectual da instituição, bem como promover e acompanhar o relacionamento das ICT que lhe sejam vinculadas com pessoas naturais ou jurídicas que exerçam empresa, no que respeita a atividades de geração e difusão de conhecimento inovador ${ }^{20}$.

\footnotetext{
${ }^{15}$ Cf. Lei $n^{\circ} 8.958 / 1994$, Art. $1^{\circ}$.

${ }^{16}$ Cf. Lei n ${ }^{\text {o }} 10.973 / 2004$, Art. 18, parágrafo único. Cf., também, Lei no 8.958/1994, Art. $3^{\circ}, \S 1^{\text {o․ }}$

${ }^{17}$ Cf. C.F., Art. $165, \S 5^{\circ}$.

${ }^{18} \mathrm{Cf}$. Lei $\mathrm{n}^{\mathrm{o}} 10.973 / 2004$, Art. 16.

${ }^{19} \mathrm{Cf}$. Lei n ${ }^{\mathrm{o}} 8.958 / 1994$, Art. $1^{\mathrm{o}}, \S 8^{\circ}$.

${ }^{20}$ Cf. Lei $n^{\circ} 10.973 / 2004$, Art. 15-A, incisos I a VIII.
} 


\section{UNIVERSIDADE FEDERAL E ATIVIDADE EMPREENDEDORA}

O marco legal da inovação trouxe a normatização de figuras jurídicas que estimulam a ampla interação entre as ICTs e o empreendedorismo inovador, tanto no campo tecnológico como no social.

Para incentivar a interação entre ICTs e o empreendedorismo inovador, modificações foram implementadas nos formatos de alianças estratégicas voltadas à pesquisa científica e ao desenvolvimento de inovações, bem como nos modelos de ambientes promotores de inovação. Verifica-se, também, o aperfeiçoamento de instrumentos jurídicos utilizados para a formalização dessas interações, com a edição de rol exemplificativo de instrumentos de estímulo ao empreendedorismo inovador, o que se passa a analisar.

\subsection{Formatos de Ambientes Promotores de Inovação}

O marco legal da inovação alterou a Lei 10.973/2004 para permitir que as ICTs e os empreendedores inovadores possam, em conjunto, criar e gerir ambientes promotores de inovação, ou seja, o parque tecnológico, o polo tecnológico e a incubadora.

Previsto na redação original da Lei 10.973/2004, o parque tecnológico é atualmente definido como o complexo planejado de desenvolvimento empresarial e tecnológico, promotor da cultura da inovação, da competitividade industrial, da capacitação empresarial e de sinergia entre atividades de pesquisa científica, de desenvolvimento tecnológico e de inovação, aproximando sujeitos que exercem empresa e uma ou mais ICTs, com ou sem vínculo entre si. ${ }^{21}$

Trata-se de estrutura física apta a receber e a reunir a sede ou a filial de empresários e pessoas jurídicas empresárias, que se reúnem com o objetivo específico de somar esforços para colocar produtos ou processos inovadores no mercado.

Outro ambiente promotor da inovação, já conhecido pelos agentes econômicos, que também recebe definição legal é o polo. Trata-se de ambiente industrial e tecnológico caracterizado pela presença dominante de sujeitos que exercem empresa e que, incluídos nas categorias de micro, pequena e empresa de médio porte, desenvolvem atividades em áreas correlatas num determinado espaço geográfico, com vínculos operacionais com a ICT, ali organizando recursos humanos, laboratórios e equipamentos de modo predisposto ao

\footnotetext{
${ }^{21}$ Cf. Lei $n^{\circ} 10.973 / 2004$, Art. $2^{-}$, X.
} 
intercâmbio entre os envolvidos para consolidação, marketing e comercialização de novas tecnologias $^{22}$.

No caso do polo, ocorre a união de ICT com organizações empresariais, bem como a conjugação de esforços para colocar novas tecnologias no mercado. Todavia, não há necessariamente a criação de um estabelecimento próprio para sediá-lo, sendo que cada organização empresarial continua atuando em sede ou filial própria.

A incubadora, que também já era mencionada na redação original da Lei 10.973/2004, recebeu adjetivação, agora chamada de incubadora de empresas, e passou a ser definida em lei como a organização ou estrutura que objetiva estimular ou prestar apoio logístico, gerencial e tecnológico ao empreendedorismo inovador e intensivo em conhecimento, com o objetivo de facilitar a criação e o desenvolvimento de organizações empresariais que tenham como diferencial a realização de atividades voltadas à inovação ${ }^{23}$.

Visto o tratamento legal conferido aos ambientes voltados à promoção da inovação e do empreendedorismo inovador em que a universidade federal pode participar, seja da criação ou da gestão de conhecimento inovador, importa analisar as alianças estratégicas que ela poderá implementar.

\subsection{Alianças Estratégicas: A Extensão Tecnológica e a Parceria}

Outro aspecto que pode ser observado como estímulo à formação de interações entre a universidade e os empreendedores inovadores é a extensão tecnológica, definida legalmente como atividade que auxilia no desenvolvimento, aperfeiçoamento, na difusão de soluções tecnológicas e na sua disponibilização à sociedade e ao mercado ${ }^{24}$.

Sobre o tema, rememore-se que Constituição brasileira prescreve o princípio da indissociabilidade entre o ensino, a pesquisa e a extensão e determina que as universidades realizem essas atividades conjuntamente ${ }^{25}$. Por conseguinte, a Lei 9.394/1996 ${ }^{26}$ reforça a efetividade da dicção constitucional, reconhecendo o dever de as universidades realizarem pesquisa e extensão ${ }^{27}$. Assim, reitera-se a relevância inequívoca da extensão, registrando-se que a referida lei considera a realização de atividades de extensão como finalidade da

\footnotetext{
${ }^{22}$ Cf. Lei no ${ }^{\circ} 10.973 / 2004$, Art. 2º, XI.

${ }^{23}$ Cf. Lei $\mathrm{n}^{\circ} 10.973 / 2004$, Art. 2으. III-A.

${ }^{24}$ Cf. Lei no $10.973 / 2004$, Art. 2o, XII.

${ }^{25}$ Cf. Constituição da República Federativa do Brasil de 1988, Art. 205.

${ }^{26}$ Cf. Lei 9.394/1996, que estabelece as diretrizes e bases da educação nacional.

${ }^{27}$ Cf. Lei no 9.394/1996, Art. 53, Parágrafo único, IV.
} 
educação de nível superior, cabendo sua inserção acadêmica formal como programa, projeto, prestação de serviços, evento ou curso ${ }^{28}$.

Percebe-se, pois, que a realização da extensão universitária é dever constitucional e legal, o qual progressivamente vem ganhando contornos de “(...) processo interdisciplinar, educativo, cultural, científico e político que promove a interação transformadora entre Universidade e outros setores da sociedade" 29 .

A extensão, que vem sendo progressivamente dissociada de traços assistencialistas, pode ser hoje percebida como prática que interliga ações de ensino e pesquisa com as demandas da sociedade. Essa prática pressupõe relação interativa entre a sociedade e a universidade, promovendo um fluxo de conhecimento de mão dupla: nele se aplica o conhecimento acadêmico já adquirido e produzido a partir de demandas da sociedade; mas, por outro lado, os atores envolvidos nas atividades de extensão, quais sejam, professores, alunos e demais participantes, adquirem conhecimentos adicionais, os quais, por sua vez, permitem aos integrantes da atividade extensionista o aprimoramento do ensino e do próprio conhecimento, quando direcionado à solução dos problemas da coletividade. (DINIZ; NEVES, 2015, p.3-4).

Assim, a Lei 10.973/2004 foi alterada de forma positiva e em consonância com a concepção segundo a qual o estudante e os integrantes da comunidade na qual se desenvolve a ação de extensão não devem ser considerados como mero receptáculo de conhecimentos validados por professores, e são chamados a se tornarem participantes do processo de construção e aplicação do conhecimento. (FORPROEX, 2012, p. 19). Desse modo, a extensão, como atividade acadêmica, pode provocar mudanças e relevantes impactos na área tecnológica industrial e social, incluído aqui o empreendedorismo.

No que se refere à possibilidade de celebração de acordos de parceria, manteve-se a autorização anteriormente prevista para as universidades celebrá-los com instituições públicas e privadas para a realização de atividades conjuntas de pesquisa científica e tecnológica e de desenvolvimento de tecnologia, produto, processo, agora se somando a esses, a prestação de serviço a respeito de conhecimento inovador ${ }^{30}$.

\footnotetext{
${ }^{28}$ Cf. Lei no 9.394/1996, Art. 43, VII e Art. 44, IV.

${ }^{29}$ Cf. Concepção do Fórum Nacional dos Pró-Reitores de Extensão das Universidades Públicas. Disponível em: <http://www.renex.org.br/documentos/2012-07-13-Politica-Nacional-de-Extensao.pdf>. Acesso em: 05 dez. 2014. ${ }^{30}$ Cf. Lei no 10.973/2004, Art. 9ㅇ․
} 
Registre-se que não só é possível usar mais de uma forma de aliança e de ambiente, como ainda combiná-los, o que dependerá da política de inovação da universidade e do seu respectivo regulamento.

\subsection{Figuras Jurídicas para Formalizar Interações entre a Universidade e o Empreendedorismo Inovador}

Com o aperfeiçoamento de vários dispositivos legais, registre-se a supressão de parte dos obstáculos legais e burocráticos referentes aos meios jurídicos que viabilizam interações entre a universidade e os empreendedores inovadores tecnológicos e sociais (OLIVEIRA, 2004, p. 11), a ver:

a) Cessão de uso de imóveis.

Uma novidade refere-se à autorização expressa para a União, os Estados, o Distrito Federal, os Municípios, as respectivas agências de fomento e as universidades cederem o uso de imóveis de sua propriedade ${ }^{31}$ diretamente aos sujeitos que exercem empresa e às ICTs interessadas para instalar e consolidar ambientes promotores da inovação, quais sejam, o parque tecnológico, o polo tecnológico e a incubadora de empresas.

b) Compartilhamento de laboratórios, equipamentos, instrumentos, materiais $e$ demais instalações.

A universidade poderá compartilhar bens móveis e imóveis com outra ICT ou organização empresária, ao realizar ações voltadas à produção de inovação tecnológica para a consecução de atividades de incubação, desde que não haja prejuízo de suas atividades finalísticas $^{32}$. Note-se que, anteriormente, essa possibilidade restringia-se às organizações empresárias que estivessem incluídas nas categorias de microempresa (ME) ou empresa de pequeno porte $(\mathrm{EPP})$. A supressão de tal restrição leva à conclusão que o compartilhamento pode ser celebrado com empresários, empresas individuais de responsabilidade limitada e sociedades empresárias nacionais ou estrangeiras de qualquer porte.

c) Permissão de uso de laboratórios, equipamentos, instrumentos, materiais e demais instalações.

Desde que não obste ou conflite com a finalidade da ICT, esta pode permitir o uso de suas instalações aos sujeitos de qualquer nacionalidade, brasileira ou não, que exerçam

\footnotetext{
${ }^{31}$ Cf. Lei $n^{\circ} 10.973 / 2004$, Art. $3^{\circ}-B$, $\S 2^{\circ}$, I.

${ }^{32} \mathrm{Cf}$. Lei ${ }^{\circ} 10.973 / 2004$, Art. $4^{\circ}$, I.
} 
empresa e às pessoas naturais em geral, para o desenvolvimento de atividades voltadas à pesquisa, ao desenvolvimento e à inovação ${ }^{33}$. Relembre-se que tal possibilidade antes se restringia aos sujeitos que exercessem empresa e que fossem de nacionalidade brasileira, bem como as organizações de direito privado sem fins lucrativos.

Nos três casos acima referidos, a universidade deverá receber contrapartida, mas agora tal remuneração poderá ter natureza financeira ou não financeira, conforme os termos do regulamento, no caso de cessão de uso de imóvel, ou do contrato ou do convênio, no caso do compartilhamento e permissão de uso. Registre-se que, nestes dois últimos casos, deve-se ainda observar o prazo para sua celebração, o qual deve ser por período determinado.

d) Transferência de tecnologia.

A universidade pode celebrar contrato de transferência de tecnologia e de licenciamento para outorga de direito de uso ou de exploração de criação que desenvolveu isoladamente ou por meio de parceria ${ }^{34}$. Nesta hipótese, além de o desenvolvimento da tecnologia agora poder ser realizado mediante contrato de parceria, é possível publicar o edital para chamada de interessados em realizar a contratação da cláusula de exclusividade no próprio sítio eletrônico da universidade, como disponível na Internet.

Outra novidade que merece registro é a dispensa de publicação de edital para a própria parceira contratar cláusula de exclusividade, quando a tecnologia for resultante da sua parceria firmada com a universidade e a remuneração tiver sido definida em instrumento jurídico próprio.

\section{e) Permissão de uso de capital intelectual.}

A universidade pode permitir o uso do conhecimento acumulado pelo seu pessoal e que seja passível de aplicação em projetos de pesquisa, desenvolvimento e inovação ${ }^{35}$, sendo que tal permissão deve ser objeto de adicional regulamentação pela universidade. Observe-se que, em grande medida, a Lei $12.772 / 2012^{36}$ traz os contornos do que pode ser permitido e sobre os limites que devem ser observados pelos docentes para atuarem nas atividades de desenvolvimento e difusão de conhecimento inovador.

\section{f) Participação minoritária do Estado em sociedade empresária.}

A União, os demais entes federativos e suas entidades autorizadas podem, nos termos de regulamento, participar minoritariamente do capital de sociedades empresárias com o

\footnotetext{
${ }^{33}$ Cf. Lei $\mathrm{n}^{\mathrm{o}} 10.973 / 2004$, Art. $4^{\mathrm{o}}$, II.

${ }^{34}$ Cf. Lei ${ }^{\circ} 10.973 / 2004$, Art. $6^{\circ}$, caput, $\$ 1^{\circ}$ e $\$ 2^{\circ}$.

${ }^{35}$ Cf. Lei n ${ }^{\mathrm{o}} 10.973 / 2004$, Art. $4^{\mathrm{o}}$, III,

${ }^{36} \mathrm{Cf}$. Lei $\mathrm{n}^{\mathrm{o}}$ 12.772/2012, que dispõe sobre a estruturação do plano de carreiras e cargos do magistério federal.
} 
propósito de realizar investimento para estimular o desenvolvimento de produtos ou processos inovadores, desde que ele esteja devidamente alinhado com as diretrizes e as prioridades definidas nas políticas de ciência, tecnologia, inovação e desenvolvimento industrial de cada esfera de governo ${ }^{37}$. (FERRAZ; NEVES, 2014, p. 63-89).

A participação de ente público em sociedades empresárias para fins de inovação foi objeto de aperfeiçoamentos. Nessa linha, resolveu-se a questão, antes controversa, sobre a titularidade da propriedade intelectual resultante do investimento estatal, podendo pertencer à sociedade empresária que receber o investimento do ente público, nos termos da lei vigente e dos atos constitutivos ${ }^{38}$. Adicionalmente, instituiu-se expressamente a possibilidade de o poder público impor, como condição do seu investimento, que a propriedade intelectual seja licenciada para atender a interesse público ${ }^{39}$ e de se dispensar a licitação para se alienar os ativos da sociedade com participação minoritária de ente público ${ }^{40}$.

A legislação editada permite entender que a participação minoritária do ente público nestes termos deverá ser temporária, por estabelecer que os recursos decorrentes da alienação da referida participação societária serão aplicados em novas pesquisas ou em novas participações societárias $^{41}$.

O ente público poderá constituir participação societária com direito de voto dotado de poderes especiais, inclusive com a possibilidade de vetar a deliberação de certas matérias ${ }^{42}$, podendo integralizar sua participação com contribuição financeira ou não financeira, economicamente mensurável, inclusive com transferência de tecnologia e licenciamento de uso ou exploração de criação de titularidade da União e de suas entidades ${ }^{43}$.

Ressalte-se que há, porém, relevantes aspectos desse instituto que poderiam ter sido detalhados para aperfeiçoar sua aplicabilidade e que devem merecer atenção quando for objeto de regulamentação, como se exemplifica a seguir.

Sendo a universidade federal constitucionalmente dotada de autonomia administrativa e financeira ${ }^{44}$, a norma hoje contida no art. $5^{\circ}$ da Lei $10.973 / 2004$ por si só já concederia a autorização legal necessária e suficiente para ela se tornar investidora no capital de sociedades empresárias, quando feito com o propósito especifico de desenvolvimento de

\footnotetext{
${ }^{37}$ Cf. Lei no $10.973 / 2004$, Art. $5^{\circ}$, caput.

${ }^{38} \mathrm{Cf}$. Lei ${ }^{\circ} 10.973 / 2004$, Art. $5^{\circ}, \S 1^{\circ}$.

${ }^{39}$ Cf. Lei ${ }^{\circ} 10.973 / 2004$, Art. $5^{\circ}$, $2^{\circ}$.

${ }^{40}$ Cf. Lei ${ }^{\circ} 10.973 / 2004$, Art. $5^{\circ}, \S 3^{\circ}$.

${ }^{41}$ Cf. Lei ${ }^{\circ} 10.973 / 2004$, Art. $5^{\circ}, \S^{\circ}$.

${ }^{42}$ Cf. Lei ${ }^{\circ} 10.973 / 2004$, Art. $5^{\circ}, \S 5^{\circ}$.

${ }^{43}$ Cf. Lei no $10.973 / 2004$, Art. $5^{\circ}$, $6^{\circ}$.

${ }^{44}$ Cf. Decreto-lei n ${ }^{\circ}$ 200/1967, Art. 26.
} 
produtos ou processos inovadores (FERRAZ; NEVES, 2014, p. 66-68). Entretanto, será de grande auxílio que tal exegese seja expressa em texto legal e que fique clara a desnecessidade de qualquer outro ato autorizativo para a universidade se valer dessa possibilidade.

Do mesmo modo, por se subentender que essa participação minoritária será temporária conforme a Lei de Licitações, pode-se propor que o prazo determinado seja, em princípio, de até 120 meses $^{45}$. Evidentemente, mostra-se mais adequado não deixar margem para dúvidas, prevendo-se esse prazo no regulamento da Lei 10.973/2004.

Outro ponto a ser tratado sobre essa participação refere-se a explicitar como será feito o processamento contábil para que o ente público receba os dividendos decorrentes da partilha dos resultados da sociedade durante o período em que for sócio quotista ou acionista.

Por fim, a função de representante do ente público para exercer o direito de voto e de fiscalização da gestão da sociedade também merece atenção. No caso da universidade federal, será, a pessoa natural que recebe essas atribuições, professor ou servidor técnicoadministrativo? No caso de um ou de outro, além dos encargos inerentes à carreira, assumirá mais este? E como será regida a sua responsabilidade administrativa, civil e penal? Perceba-se que o silêncio do regulamento sobre tais questões pode levar ao desinteresse em se assumir tal encargo e à inviabilidade prática da utilização do próprio instituto da participação societária minoritária pela universidade federal, o que pode estimular, mais uma vez, a delegação de tarefas para as fundações de apoio.

Ainda sobre responsabilidade civil, é preciso que fique claro sobre como será disciplinada a possível e eventual responsabilização do ente público por dívidas da sociedade empresária perante terceiros, seja em causas trabalhistas, seja em causas judiciais que envolvam reparação de danos aos direitos do consumidor, ao meio ambiente, às vítimas de infrações à livre concorrência e em causas judiciais em que se discutam débitos fiscais.

Veja-se, também, que não há clareza a respeito de qual formato societário deve adotar a pessoa jurídica que receberá o investimento público, indagando-se se ela deverá obrigatoriamente adotar o formato de sociedade anônima ou poderá adotar o formato de sociedade limitada, bem como sobre se haverá a instituição de mecanismo próprio para afastar a responsabilização de ente público pelas dívidas da pessoa jurídica perante terceiros.

Qualquer que seja o tipo societário a ser permitido, mostra-se necessária a alteração da Lei Complementar n. 123/06 para permitir que as sociedades empresárias, inclusive as

\footnotetext{
${ }^{45}$ Cf. Lei ${ }^{\circ} 8.666 / 1993$, Art. 57, V.
} 
sociedades anônimas ${ }^{46}$, que realizem atividades voltadas para pesquisa, desenvolvimento e inovação e que tenham o ente público como sócio quotista ou acionista, possam ser enquadradas nas categorias de ME ou EPP, como também autorizadas a se valer da inscrição no regime jurídico tributário diferenciado correspondente ao chamado "SIMPLES NACIONAL" $" 47$.

Aspectos dessa natureza, se esclarecidos em lei, ou, pelo menos, no regulamento da Lei 10.973/2004, em muito auxiliarão para que o instituto em comento de fato possa ser utilizado.

g) Prestação de serviços técnicos especializados.

A universidade poderá prestar às instituições públicas ou privadas serviços técnicos especializados, desde que compatíveis com os objetivos da Lei 10.973/2004, os quais, como já referido, não estão mais restritos a incentivar a criação de produtos e processos de uso exclusivo e objetos de proteção pela via do segredo empresarial.

Desse modo, o marco legal da inovação alargou o leque de serviços técnicos especializados que a universidade pode prestar. Isso porque, como antes descrito, diante do novo conceito de inovação, os objetivos da Lei de Inovação foram ampliados, sendo certo que qualquer serviço inovador que resulte em melhorias e em efetivo ganho de qualidade ou desempenho poderá ser prestado pela universidade, devendo concentrar-se em, dentre outros possíveis resultados, incrementar a competitividade das organizações empresárias ${ }^{48}$.

Outra novidade trazida pelo marco legal da inovação quanto à prestação de serviços técnicos especializados refere-se à possibilidade de o representante legal máximo da instituição, a quem compete decidir que serviços serão prestados pela universidade, delegar a outras autoridades o poder de conceder essa autorização. Poderá, inclusive, delegá-lo a mais de uma autoridade, apenas sendo vedada a subdelegação ${ }^{49}$.

\subsection{Instrumentos Jurídicos de Estímulos à Inovação}

Importante registrar que a Lei 10.973/2004 trouxe, no $\S 2^{\circ}$-A, do art. 19, incisos I a XII, a previsão de rol numerus apertus de instrumentos jurídicos, os quais já vinham sendo utilizados por entes públicos e privados para estimular a inovação nas organizações

\footnotetext{
${ }^{46}$ Cf. Lei Complementar $n^{\text {o }} 123 / 06$, Art. $3^{\circ}, \S 4^{\circ}, X$.

${ }^{47}$ Cf. Lei Complementar $n^{\circ} 123 / 06$, Art. 17, III.

${ }^{48}$ Cf. Lei $n^{\circ} 10.973 / 2004$, Art. $8^{\circ}$.

${ }^{49}$ Cf. Lei $n^{\circ} 10.973 / 2004$, Art. $8^{\circ}, \S 1^{\circ}$ e $\$ 2^{\circ}$.
} 
empresárias. Essa previsão expressa em lei não só reforça a autorização para a sua utilização como também induz a divulgação, o incentivo e o aperfeiçoamento de sua utilização por entes federais, estaduais e municipais. (CGEE. ANPEI, 2009).

A relação é ampla e feita sem o propósito de ser taxativa, sendo que cada um dos instrumentos ali previstos pode ser utilizado de forma isolada ou em combinação, inclusive com o uso de figuras jurídicas atípicas, ou seja, não tipificadas em lei.

Há a previsão de três classes de concessão de recursos públicos sem a necessidade de reembolso: a subvenção econômica, que consiste na concessão de recursos públicos não reembolsáveis ${ }^{50}$; o bônus tecnológico, que se trata de espécie de subvenção econômica concedida aos sujeitos enquadrados nas categorias de ME e de EPP, por meio de previsão de dotações orçamentárias de órgãos ou entidades da administração pública, destinadas ao pagamento de compartilhamento ou uso de infraestrutura para pesquisa ou desenvolvimento tecnológicos, contratação de serviços tecnológicos especializados, ou transferência de tecnologia meramente complementar àqueles serviços nos termos do regulamento ${ }^{51}$; e a concessão de bolsas, outra espécie de subvenção destinada às pessoas naturais para remunerálas por serviços prestados conforme prévio plano de trabalho acertado ${ }^{52}$.

A Lei 10.973/2004 também prevê instrumentos que podem ser utilizados tanto por entes públicos quanto por sujeitos privados para estimular à inovação, quais sejam: o financiamento, concebido como contrato de empréstimo com previsão de aplicação em finalidade específica ${ }^{53}$; a participação societária estabelecida de forma ampla, podendo ensejar a realização de investimentos em quotas ou ações, conforme o tipo societário que tiver sido utilizado para revestir a sociedade empresária ${ }^{54}$; a encomenda tecnológica ${ }^{55}$, assim, um novo produto ou serviço resultante de desenvolvimento científico e/ou tecnológico que pode ser solicitado por particular ou pelo Estado com o objetivo de atender a demandas sociais específicas e que envolvem elevado risco e custo (RAUEN, 2014, p. 50); os fundos de investimento, ou seja, a modalidade de investimento coletivo criada por administrador que lhe define prazos, objetivos, políticas, categorias dos ativos, taxas, regras gerais e os tipos de investimentos em renda fixa, ações, cambiais ou multimercado ${ }^{56}$. Registre-se, para melhor se

\footnotetext{
${ }^{50}$ Cf. Lei no $10.973 / 2004$, Art. $19, \S 2^{\circ}$-A, I.

${ }^{51}$ Cf. Lei $n^{\circ} 10.973 / 2004$, Art. 19, $\$ 2^{\circ}$-A, IV.

${ }^{52}$ Cf. Lei no $10.973 / 2004$, Art. 19, $\$ 2^{\circ}$-A, VII.

${ }^{53}$ Cf. Lei no $10.973 / 2004$, Art. 19, $2^{\circ}$-A, II.

${ }^{54}$ Cf. Lei $n^{\circ} 10.973 / 2004$, Art. 19, $\$ 2^{\circ}$-A, III.

${ }^{55}$ Cf. Lei no ${ }^{\circ} 10.973 / 2004$, Art. 19, $\$ 2^{\circ}$-A,V.

${ }^{56} \mathrm{Cf}$. Lei $\mathrm{n}^{\mathrm{o}}$ 10.973/2004, Art. 19, §2 $2^{\circ}$-A, IX.
} 
entender estes fundos, que eles se formam mediante comunhão de recursos e são constituídos sob a forma de condomínio, destinado à aplicação em ativos financeiros. Eles podem adotar modalidade aberta ou fechada, sendo que, no primeiro caso, o resgate é permitido conforme o regulamento, e no segundo, apenas ao término do prazo de duração ${ }^{57}$; os fundos de participação, isto é, modalidade de fundo de investimento necessariamente destinado ao investimento em organizações empresárias ${ }^{58}$. Esclareça-se a respeito destes, que são constituídos sob a forma de condomínio fechado e representam comunhão de recursos destinados à aquisição de ações, bônus de subscrição, debêntures simples, outros títulos e valores mobiliários conversíveis ou permutáveis em ações de emissão de companhia, abertas ou fechadas, como títulos e valores mobiliários representativos de participação em sociedades limitadas, que deve participar do processo decisório da sociedade investida com efetiva influência na definição de sua política estratégica e na sua gestão ${ }^{59}$; e, por fim, os títulos financeiros em geral, incentivados ou não ${ }^{60}$.

Além dos acima referidos, estão presentes instrumentos direcionados especificamente aos estímulos que podem ser concedidos por entes públicos como os

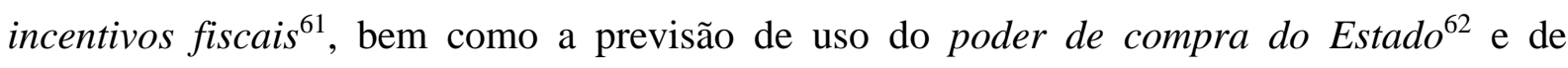
investimento em pesquisa e desenvolvimento em contratos públicos de concessão ou em regulações setoriais ${ }^{63}$.

\section{CONCLUSÃO}

Como se vê, o marco legal da inovação implantou mudanças positivas para o desempenho da universidade federal em sua tarefa constitucional de gerar e transferir conhecimento inovador à sociedade e ao mercado. No âmbito do Direito Público, houve a ampliação de institutos e entraves foram suprimidos. No campo do Direito Privado, figuras jurídicas foram previstas expressamente e outras foram aperfeiçoadas para incentivar a pesquisa científica, tecnológica e de inovação.

\footnotetext{
${ }^{57}$ Cf. Instrução Normativa CVM no $555 / 2014$, Arts. $3^{\circ}$ e 108.

${ }^{58}$ Cf. Lei ${ }^{\circ} 10.973 / 2004$, Art. $19, \S 2{ }^{\circ}-A, X$.

${ }^{59} \mathrm{Cf}$. Instrução Normativa CVM n ${ }^{\circ} 578 / 2016$, art. $5^{\circ}$.

${ }^{60}$ Cf. Lei n ${ }^{\circ} 10.973 / 2004$, Art. $19, \S 2^{\circ}$-A, XI.

${ }^{61} \mathrm{Cf}$. Lei ${ }^{\circ} 10.973 / 2004$, Art. $19, \S 2^{\circ}$-A, IV.

${ }^{62}$ Cf. Lei no $10.973 / 2004$, Art. 19, §2 $2^{\circ}$-A,VIII.

${ }^{63}$ Cf. Lei no $10.973 / 2004$, Art. 19, $\$ 2^{\circ}$-A, XII.
} 
Ressalte-se, no entanto, que a autonomia constitucionalmente determinada à universidade permanece em construção, cabendo acompanhar, diante das mudanças legais, como será a colaboração entre esta e a fundação de apoio, destacando-se o aspecto de que são concebidos como entes independentes que se relacionam principalmente por contratos.

Percebe-se, como resultado central, o maior aparelhamento das ICTs em geral, e da universidade federal em particular, para colaborar com a atividade estatal e com a atividade empresarial em matéria de inovação, não mais circunscrita a projetos orientados para a produção de propriedade intelectual, voltada a garantir o uso exclusivo de inovações. Como visto, há ampla autorização para firmar parcerias a fim de entregar para qualquer parcela da sociedade - serviços públicos ou mercado -, novidade ou aperfeiçoamento que resulte em novos produtos, serviços ou processos, ou que agreguem novas funcionalidades ou características a produto, serviço ou processo, promovendo melhorias em qualidade ou desempenho.

Ainda há muito a fazer, em termos de regulamentação da Lei 10.973/2004, bem como de definição da política de inovação por parte de cada ICT, em especial a universidade federal. Reconheça-se, no entanto, a edição de avanços normativos relevantes, que merecem ser considerados diante de impactos que já começam a ser sentidos por todos os atores envolvidos na produção, difusão e emprego de conhecimento inovador.

\section{REFERÊNCIAS BIBLIOGRÁFICAS}

BENOÎT, Godin. Innovation: the history of a category. Project on the intellectual history of innovation. Working Paper n. 1, 2008. Disponível em http://www.csiic.ca/PDF/IntellectualNo1.pdf. Acesso em:19 set. 2016.

CGEE. ANPEI. Os novos instrumentos de apoio à inovação: uma avaliação inicial. Brasília: Centro de Gestão e Estudos Estratégicos - Associação Nacional de Pesquisa e Desenvolvimento, 2009. Disponível em

<http://www.cgee.org.br/atividades/redirect.php?idProduto=5613> Acesso em 08 set. 2016. 
DINIZ, Davi Monteiro. A estranha autarquia: da desagregação do regime jurídico constitucional universitário por leis administrativas e seus efeitos nas universidades federais. In: DIAS, Maria Tereza Fonseca. SILVA, Lucas Gonçalves da. CALDAS, Roberto Correia da Silva Gomes. Direito administrativo e gestão pública I. Florianópolis: CONPEDI, 2015. p. 240-268. Disponível em <http://www.conpedi.org.br/publicacoes/66fsl345/1ppyi8tz/hoXX31Bq4blWEWp9.pd> Acesso em: 04 set. 2016.

DINIZ, Davi Monteiro. NEVES, Rubia Carneiro. Direito empresarial atualizado e acessível: produção e publicação de material didático na internet a partir de projeto de extensão. Congresso de Inovação e Metodologias de Ensino(2015): Disponível em: <https://congressos.ufmg.br/index.php/congressogiz/congresso-giz-2015/paper/view/103/25> Acesso em 09 set. 2016.

. Universidade e tecnologia empresarial: tempo de revisar a Lei de Inovação. In: JOÃO, Maraluce Maria Custódio. ASSAFIM, Marcelo De Lima. Direito, inovação, propriedade intelectual e concorrência. Florianópolis: CONPEDI, 2015. p.141-161. Disponível em: <http://www.conpedi.org.br/publicacoes/66fsl345/2oq57zr8/D4NBk9XpcvNVqbFu.pd> Acesso em 04 set. 2016.

FERRAZ, Luciano. NEVES, Rubia Carneiro. Parcerias na Lei de Inovação Tecnológica? O caso das sociedades de propósito específico (SPE). Revista de Informação Legislativa, v. 203, n.51, p. 63-89, jul./set. 2014. Disponível em: < https://www2.senado.leg.br/bdsf/bitstream/handle/id/507408/001017659.pdf?sequence=1> Acesso em: 04 set. 2016.

FORPROEX. Política nacional de extensão universitária. Fórum Nacional dos PróReitores de Extensão das Universidades Públicas. Disponível em: <http://www.renex.org.br/documentos/2012-07-13-Politica-Nacional-de-Extensao.pdf〉. Acesso em: 05 dez. 2014.

LAPERCHE, Blandine. UZUNIDIS, Dimitri. La valorisation de la recherche publique en France et la question de l'université. Working Papers/Laboratoire de Recherche sur l'Industrie et 
l'Innovation (Lab.RII), Université du Littoral Côte d'Opale, 2010. Disponível em: http://rrifr.univlittoral.fr/wp-content/uploads/2010/07/doc16.pdf. Acesso em: 19 set. 2016.

OLIVEIRA, Edson Marques. Empreendedorismo social no Brasil: atual configuração, perspectivas e desafios - notas introdutórias. Revista FAE, Curitiba, v.7, n.2, p.11-18, jul./dez. 2004. Disponível em: 〈http://dns.ts.ucr.ac.cr/binarios/pela/pl-000526.pdf〉. Acesso em 26 ago. 2016.

RAUEN, André Tortado. Encomendas tecnológicas nos Estados Unidos: possibilidades do regulamento federal de aquisições. Radar, n. 36, 2014, p. 49-56. Disponível em: <http://repositorio.ipea.gov.br/bitstream/11058/3856/1/Radar_n36_encomendas.pdf> Acesso em 20 set. 2016.

RAUEN, Cristiane Vianna. O novo marco legal da inovação no Brasil: o que muda na relação ICT-empresa? Radar. V. 43, p. 21-35, fev. 2016. Disponível em: < http://repositorio.ipea.gov.br/bitstream/11058/6051/1/Radar_n43_novo.pdf> Acesso em 25 ago. 2016. 